Стычинский А. С., д-р мед. наук, заведующий отделом электрофизиологии и рентгенохирургических методов лечения аритмий сердца

Альмиз П. А., канд. мед. наук, ведущий научный сотрудник отдела электрофизиологии и рентгенохирургических методов лечения аритмий сердца

Ящук Н.С., врач-хирург отделения врожденных пороков сердца

Мельник Н. В., врач-кардиолог отделения нарушения ритма сердца

Топчий А. В., ведущий научный сотрудник отдела электрофизиологии и рентгенохирургических методов лечения аритмий сердца

Поканевич А. В., врач-кардиолог отделения нарушения ритма сердца

Лозовой А. А., врач-хирург отделения врожденных пороков сердца

ГУ «Национальный институт сердечно-сосудистой хирургии имени Н. М. Амосова НАМН Украины», г. Киев, Украина

\title{
Катетерное лечение фибрилляции предсердий после пластики дефекта межпредсердной перегородки
}

Резюме. Дефект межпредсердной перегородки (ДМП) является одним из наиболее распространенных врожденных пороков сердца (ВПС). Для этого порока характерно развитие предсердных тахиаритмий, таких как предсердные макрориэнтри и фибрилляция предсердий (ФП).

Целью данного исследования является анализ нашего первого опыта катетерного лечения ФП у пациентов после пластики ДМП.

Материалы и методы. В работе представлены данные катетерных процедур по устранению ФП у трех пациентов в возрасте 40, 42 и 50 лет, которым ранее была произведена пластика ДМП. Время, прошедшее с момента хирургической коррекции порока, $-23,16$ и 40 лет соответственно; длительность существования аритмии - 3, 5 и 5 лет. Для сравнения представлены результаты 26 первичных катетерных процедур по лечению ФП у пациентов без сопутствующей структурной патологии сердца. Особенностью методики устранения аритмии в первой группе являлось применение чреспищеводной и внутрисердечной эхокардиографии (ЭхоКГ) при проведении транссептальной пункции.

Результаты. В сроки от 14 до 16 месяцев у всех пациентов сохраняется синусовый ритм. У одного из пациентов через 6 месяцев после процедуры возник пароксизм ФП. В дальнейшем на фоне проводимой антиаритмической терапии рецидивов аритмии не было.

В группе пациентов без сопутствующей структурной патологии в сроки от 14 до 18 месяцев рецидивы аритмии отсутствовали у 20 (76,9\%) из 26 пациентов. У 2 из 6 пациентов с рецидивами ФП после назначения антиаритмической терапии синусовый ритм сохраняется в течение более 6 месяцев.

Ключевые слова: фибрилляция предсердий, радиочастотная абляция, изоляция устьев легочных вен, врожденные пороки сердиа, дефект межпредсердной перегородки.

Дефект межпредсердной перегородки (ДМП) является одним из наиболее распространенных врожденных пороков сердца (ВПС) [1]. Для этого порока характерно развитие предсердных тахиаритмий, таких как предсердные макрориэнтри и фибрилляция предсердий (ФП) [2]. Эти аритмии не только ухудшают качество жизни носителей порока, но и являются причиной таких тяжелых осложнений, как инсульты и сердечная недостаточность $[1,2]$. На сегодняшний день катетерное лечение ФП является методом выбора в лечении парок- сизмальной ФП [3]. Однако это мнение касается в первую очередь лиц без сопутствующей структурной патологии сердца. Тактика в отношении пациентов с ВПС менее определена. Связано это, главным образом, с тем, что опыт таких процедур, а следовательно и оценка их эффективности, крайне малочисленны [4-7]. Результаты катетерного лечения ФП у пациентов после пластики ДМП, как правило, рассматриваются не отдельно, а в общей группе с другими ВПС. Отсюда и разница в приводимых результатах. 
Цель данного исследования - анализ нашего первого опыта катетерного лечения ФП у пациентов после пластики ДМП.

Материалы исследования. Данные катетерных процедур по устранению ФП у трех пациентов, которым ранее была произведена пластика ДМП. Возраст пациентов составлял 40, 42 и 50 лет. Время, прошедшее с момента хирургической коррекции порока, - 23, 16 и 40 лет соответственно; длительность существования аритмии - 3, 5 и 5 лет. У двух пациентов была пароксизмальная форма ФП, у одного - персистирующая. Медикаментозная терапия двумя и более антиаритмическими препаратами была неэффективной. Какиелибо другие сопутствующие ВПС у них отсутствовали.

Для сравнения представлены результаты 26 первичных катетерных процедур по лечению ФП у пациентов без сопутствующей структурной патологии сердца. Эти процедуры были последовательно произведены за тот же период (с 01.01.2018 по 01.05.2018), что и у пациентов с ДМП. Пароксизмальная форма аритмии была у 16 (62\%) пациентов этой группы.

Методика процедуры. Предоперационная подготовка включала в себя прием антикоагулянтов в течение 4-6 недель. Накануне процедуры производили чреспищеводную эхокардиографию (ЭхоКГ) с целью исключения тромбов в полостях сердца.

Катетерная процедура происходила в условиях седации и обезболивания пропофолом и фентанилом. Через правую бедренную вену производили транссептальную пункцию. Через левую бедренную вену в правое предсердие вводили датчик для эхокардиографии. Визуализация заплаты на межпредсердной перегородке осуществлялась при помощи внутрисердечной ЭхоКГ в двух случаях и чреспищеводной - в одном. После пункции заплаты в левое предсердие вводили 2 транссептальных интродъюсера (8 Fr), через один из которых устанавливали 20-полюсный циркулярный катетер для регистрации электрограмм в легочной вене, через другой - катетер для абляции. Производили сегментарную изоляцию легочных вен на основании регистрации их потенциалов. Подтверждением изоляции являлось наличие двунаправленного блока проведения между левым предсердием и легочной веной. В случаях, когда изоляция легочных вен производилась во время ФП, либо аритмия возникала в ходе процедуры, после завершения этапа изоляции проводили поиск и абляцию участков, где регистрировалась многокомпонентная графика. После окончания манипуляций в левом предсердии создавали блок проведения через кавотрикуспидальный перешеек.

В группе из 26 пациентов без сопутствующей структурной патологии сердца методика процедуры была аналогичной, с единственным отличием в том, что не применялась внутрисердечная ЭхоКГ.
Результаты. У всех трех пациентов была произведена изоляция всех легочных вен. Во всех случаях процедура начиналась на фоне синусового ритма. В одном случае в ходе процедуры спонтанно возникла ФП. Изоляция вен была завершена, а затем - в результате нанесения аппликаций в зоне с фрагментированной активностью восстановился синусовый ритм. Во всех случаях был создан блок проведения через кавотрикуспидальный перешеек. Длительность процедуры колебалась в пределах от 190 до 220 минут. Ни в одном из случаев не было каких-либо осложнений.

У всех 26 пациентов с ФП, не имеющих сопутствующей структурной патологии сердца, была выполнена изоляция всех легочных вен. У 22 пациентов создан блок проведения через кавотрикуспидальный перешеек, у 4 - подтверждено его наличие после произведенной ранее процедуры по лечению истмусзависимого трепетания предсердий. Длительность процедуры колебалась в пределах от 188 до 240 минут. Какие-либо осложнения в ходе процедуры и в послеоперационном периоде отсутствовали.

В сроки от 14 до 16 месяцев у всех пациентов сохранялся синусовый ритм. У одного из пациентов через 6 месяцев после процедуры возник пароксизм ФП. В дальнейшем на фоне проводимой антиаритмической терапии рецидивов аритмии не отмечено.

В группе пациентов без сопутствующей структурной патологии в сроки от 14 до 18 месяцев рецидивы аритмии отсутствовали у 20 (76,9\%) из 26 пациентов. У 2 из 6 пациентов с рецидивами ФП после назначения антиаритмической терапии синусовый ритм сохранялся в течение более 6 месяцев.

Обсуждение. В нашей серии наблюдений результаты катетерного лечения ФП у пациентов после пластики ДМП существенно не отличаются от таковых у пациентов без структурной патологии сердца. В немногочисленных работах по катетерному лечению ФП у лиц с ВПС, в основном, приводятся результаты лечения во всей группе, включающей различные виды пороков [4-7]. Поскольку удельный вес тех или иных видов пороков различен, то отмечается заметная разница в результатах.

В исследовании Philip F. et al. [4] в группе из 36 пациентов с ВПС, среди которых более половины (22) были после пластики ДМП, отсутствие рецидивов ФП через 300 дней после проведенного катетерного лечения имело место у 41,7 \%, а через 4 года - у 27,7 \%.

В исследовании Liang J. J. et al. [5], включающем в себя 84 наблюдения из 8 центров, через 12 месяцев после процедуры рецидивы аритмии отсутствовали у 53, $1 \%$ пациентов. Еще у 18,5 \% после назначения ранее неэффективных антиаритмических препаратов рецидивы аритмии прекратились. По степени сложности $51 \%$ ВПС в данной группе были отнесены к простым. 
Авторы не обнаружили разницы в результатах лечения в зависимости от вида порока.

Данные, приведенные в работе Sohns C. et. al. [6], более оптимистичны. В группе из 57 пациентов с ВПС, среди которых 21 были с ДМП, в том числе 18 после пластики дефекта, через 1 год после первой процедуры рецидивы ФП отсутствовали у $63 \%$, а через 5 лет - у $22 \%$. Повторные процедуры, среднее число которых составило 2,0 \pm 0,5, были произведены у $52,3 \%$ пациентов. Прогнозируемая авторами частота успешных результатов после повторных процедур через 1 год $99 \%$, через $5-83 \%$. В данном исследовании $61,4 \%$ ВПС были отнесены к простым. Авторы пришли к выводу, что результат лечения ФП при ВПС не зависит от сложности порока.

Заметно отличаются от приведенных выше, данные Guarguagli S. et al. [7]. В группе из 58 пациентов с ВПС, из которых 57 \% были отнесены к умеренно выраженным и сложным, через 1 год после процедуры синусовый ритм сохранялся у $32,8 \%$. Повторные процедуры были произведены у $60 \%$ пациентов. После второй и третьей катетерных процедур синусовый ритм в течение 1 года сохранялся у 40,9\% и $36,5 \%$ соответственно. Сложность ВПС, согласно данным авторов, была основным предиктором рецидива аритмии.

Что касается технических особенностей проведения процедуры, то пункция заплаты на межпредсердной перегородке под контролем ЭхоКГ не составила каких-либо затруднений и не привела к удлинению времени процедуры. K такому же выводу пришли Arkles J. et al. [8] на основании опыта 20 процедур у пациентов после пластики ДМП.

Выводы. Катетерное лечение ФП у лиц, перенесших пластику ДМП, эффективно и безопасно. Оно может быть рекомендовано в качестве метода выбора у данного контингента больных.

\section{Список использованных источников References}

1. Khairy P, Van Hare GF, Balaji S, Berul CI, Cecchin F, Cohen MI, et al. PACES/HRS Expert Consensus Statement on the Recognition and Management of Arrhythmias in
Adult Congenital Heart Disease. Canadian Journal of Cardiology. 2014:(30);e1-e63. https://doi.org/10.1016/j. cjca.2014.09.002

2. Hernández-Madrid A, Paul T, Abrams D, Aziz PF, Blom NA, Chen J, et al. Arrhythmias in congenital heart disease: a position paper of the European Heart Rhythm Association (EHRA), Association for European Paediatric and Congenital Cardiology (AEPC), and the European Society of Cardiology (ESC) Working Group on Grownup Congenital heart disease, endorsed by HRS, PACES, APHRS, and SOLAECE. Europace 2018:20(11);1719-53. https://doi.org/10.1093/europace/eux380

3. Calkins H, Hindricks G, Cappato R, Kim YH, Saad EB, Aguinaga L, et al. 2017 HRS/EHRA/ECAS/APHRS/ SOLAECE Expert consensus statement on catheter and surgical ablation of atrial fibrillation. Heart Rhythm. 2017:14(10); $276-\mathrm{e} 444$. hrthm.2017.05.012

4. Philip F, Muhammad KI, Agarwal S, Natale A, Krasuski RA. Pulmonary vein isolation for the treatment of drug-refractory atrial fibrillation in adults with congenital heart disease. Congenit. Heart Dis. 2012:7;392-9. https:// doi.org/10.1111/j.1747-0803.2012.00649.x

5. Liang JJ, Frankel DS, Parikh V, Lakkireddy D, Mohanty S, Burkhardt JD, et al. Safety and outcomes of catheter ablation for atrial fibrillation in adults with congenital heart disease : A multicenter registry study. Heart Rhythm. 2019:16(6);846-52. https://doi.org/10.1016/j. hrthm.2018.12.024

6. Sohns C, Nornberg JH, Hebe J, Duckeck W, Ventura R, Konietschke F, et al. Catheter ablation for atrial fibrillation in adults with congenital heart disease. J.Am.Coll.Cardiol. Clinical electrophysiology. 2018;4:733-43. https://doi. org/10.1016/j.jacep.2018.01.015

7. Guarguagli S, Kempny A, Cazzoli I, Barracano R, Gatzoulis MA, Dimopoulos K, Ernst S. Efficacy of catheter ablation for atrial fibrillation in patients with congenital heart disease. Europace. 2019;21(9):1334-44. https://doi. org/10.1093/europace/euz157

8. Arkles J, Zado E, Supple G, Frankel DS, Callans D, Marchlinski F, Dixit S. Feasibility of transseptal access in patients with previously scarred or repaired interatrial septum. J Cardiovasc Electrophysiol. 2015 Sep;26(9):9638. https://doi.org/10.1111/jce.12730

\section{Catheter Ablation for Atrial Fibrillation in Patients after Atrial Septal Defect Repair}

Stychynskyi O. S., Almiz P. O., Jaschuk N. S., Melnik N. V., Topchii A. V., Pokanevych A. V., Lozovoyi O. A. National Amosov Institute of Cardiovascular Surgery, Kyiv, Ukraine

Abstract

Atrial septal defect (ASD) is one of the most common congenital heart disorders. This defect is characterized by the development of atrial tachyarrhythmias, e.g. intra-atrial reentry or atrial fibrillation (AF).

The objective of the study was to examine the safety and efficacy of AF ablation in patients after ASD repair. Oneyear procedural success was defined as freedom from recurrent AF, off antiarrhythmic drugs (complete freedom) or off/on previously failed antiarrhythmic drugs (complete/partial freedom).

In total, 3 patients after ASD repair were included (the age was 40, 42 and 50; the time from cardiac surgery to catheter ablation was 23, 16 and 40 years; 2 patients had paroxysmal AF). Pulmonary vein isolaton was performed in 3 patients, of 
whom 2 underwent pulmonary vein isolation alone. Twenty six randomly selected patients undergoing first AF ablation at the same time period, without prior cardiac surgery and without concomitant structural cardiac pathology, were used as control. Peculiarity of ablation in the first group was the use of transesophageal and intracardiac echocardiography during transseptal puncture. Duration of the procedure was 190-220 minutes.

Complete freedom was achieved within 14-18 months in 2 cases; complete/partial freedom was achieved in 1 case (no paroxysms of AF after antiarrythmic therapy in remote period). No complications were reported. The results were similar to those in the control group where complete freedom was observed in 20 (76.9\%) and complete/partial freedom in 2 (7.7\%) patients.

AF catheter ablation in patients after ASD repair is effective and safe. It may be recommended as a priority technique for this group of patients.

Keywords: atrial fibrillation, catheter ablation, pulmonary veins isolation, congenital heart disease, atrial septal defect.

\title{
Катетерне лікування фібриляції передсердь після пластики дефекту міжпередсердної перегородки
}

\author{
Стичинський О. С., Альміз П. О., Ящук Н. С., Мельник Н. В., Топчій А. В., Поканєвич А. В., Лозовий О. А. \\ ДУ «Національний інститут серцево-судинної хірургії імені М. М. Амосова НАМН України», м. Київ, Україна
}

Резюме. Дефект міжпередсердної перегородки (ДМП) є однією з найпоширеніших вроджених вад серця (ВПС) [1]. Для цієї вади характерний розвиток передсердних тахіаритмій, таких як передсердні макроріентрі і фібриляція передсердь.

Метою цього дослідження є аналіз нашого першого досвіду катетерного лікування ФП у пацієнтів після пластики ДМП.

Матеріали та методи. У роботі представлені дані катетерних процедур щодо усунення ФП у трьох пацієнтів віком 40, 42 і 50 років, яким раніше виконано пластику ДМП. Терміни з моменту хірургічної корекції вад становили 23, 16 і 40 років відповідно; тривалість наявності аритмії - 3, 5 і 5 років. Для порівняння представлені результати 26 первинних катетерних процедур з лікування ФП у пацієнтів без супутньої структурної патології серця. Методика усунення в першій групі відрізнялася застосуванням черезстравохідної та внутрішньосерцевої ЕхоКГ під час транссептальної пункції.

Результати. У термін від 14 до 16 місяців у всіх пацієнтів зберігався синусовий ритм. В одного з пацієнтів через 6 місяців після процедури виник пароксизм ФП. У подальшому на тлі проведеної антиаритмічної терапії рецидивів аритмії не відзначено.

У групі пацієнтів без супутньої структурної патології в термін від 14 до 18 місяців рецидиви аритмії були відсутні у 20 (76,9 \%) з 26 пацієнтів. У 2 з 6 пацієнтів з рецидивами ФП після призначення антиаритмічної терапії синусовий ритм зберігався протягом більше 6 місяців.

Ключові слова: фібриляція передсердь, радіочастотна абляція, ізоляція легеневих вен, вроджені вади серия, дефект міжпередсердної перегородки.

Стаття надійшла в редакцію 12.07.2019 р. 